This is a post-refereeing, pre-publication version of the paper :

Making in-class skills training more effective: The scope for interactive videos to complement the delivery of practical pedestrian training.

James Hammond, Tom Cherrett and Ben Waterson

Published in the British Journal of Educational Technology

The official version is available at DOI: 10.1111/bjet.12205 


\title{
Making in-class skills training more effective: The scope for interactive videos to complement the delivery of practical pedestrian training.
}

\author{
James Hammond ${ }^{1}$, Tom Cherrett and Ben Waterson
}

James Hammond (Corresponding Author) is an Engineering Doctorate Researcher, Tom Cherrett a Senior Lecturer and Ben Waterson a Lecturer in the Transportation Research Group at the University of Southampton. Address for Correspondence: James Hammond, Transportation Research Group, University of Southampton, Highfield, Southampton, SO17 1BJ.Email: j.hammond@soton.ac.uk

\begin{abstract}
Skills and awareness of young pedestrians can be improved with on-street practical pedestrian training, often delivered in schools in the United Kingdom by local authorities with the intention of improving road safety. This training is often supplemented by in-class paper based worksheet activities which are seen to be less effective than practical training in that they focus on knowledge acquisition rather than directly improving the correct application of safe pedestrian skills at the roadside. Previous research indicates that interactive video tools have the potential to develop procedural skills whilst offering an engaging road safety educational experience, which could positively impact on road crossing behaviour.
\end{abstract}

In this paper, the design and development of a hazard-identification interactive road safety training video targeting child road crossing skills is presented. The interactive video was shown to be an engaging training resource for 6-7 year old children. The tool's scope for improving pedestrians' roadside skills is considered along with the wider implications for interactive video to aid safety training in other areas.

\section{Practitioner Notes}

What is already known about this topic

- Interactive video has the potential to teach procedural skills.

- $\quad$ Paper-based road safety educational materials are less effective at improving skills compared to practical experience and training.

- $\quad$ Practical pedestrian training delivered by some Local Authorities is in decline.

What this paper adds

- Interactive hazard-identification video offers an engaging educational experience for young road users.

- $\quad$ Interactive road safety videos show potential to be effective in positively improving some on-street child pedestrian behaviour.

- On-street skills assessments must be designed to reduce confounding external influences.

Implications for practice and / or policy

- Interactive video could be considered as an additional educational aid to complement existing practical road safety training.

- $\quad$ Practical training must still form the bulk of pedestrian road safety education.

- Interactive video is applicable for other skills based training that traditionally relies on the passive watching of video-based training material. 


\subsection{Introduction}

Encouraging children to walk to school to improve their health and wellbeing is of increasing importance whilst at the same time, reducing our reliance on private vehicles for the school run. In so doing, we are however increasing the exposure of young and vulnerable pedestrians to potentially dangerous environments involving traffic. With over 2000, 5-15 year old pedestrians involved in traffic related injuries whilst walking to school in Great Britain in 2010 (Department for Transport, 2011a), it is clear that injury prevention measures must be accompanied by the promotion of walking in order to minimize this risk (Pollack et al., 2012). Education, training and publicity (ETP) programmes are interventions designed to improve risk awareness and pedestrian skills (Dumbaugh and Frank, 2007) with the aim of reducing road accidents.

Child pedestrian training schemes are a key element of many ETP programmes and have become commonplace in the United Kingdom (Hammond et al., 2013). Training is seen as important, alongside walk-to-school programmes to ensure children are safe on their school journey. 'Kerbcraft' is a practical pedestrian training programme offering children training in three fundamental pedestrian skills: finding safe places and routes, crossing safely between parked cars and crossing safely at junctions. Twelve roadside sessions of approximately thirty minutes are delivered to children aged five to seven over the course of one academic year. The course is practical, taking place at the roadside with no classroom-based elements and during a national evaluation was shown to demonstrate 'strong statistical evidence of the positive impact of training in all three Kerbcraft skills' (Whelen et al., 2008). The government recommends that local authorities in the United Kingdom base pedestrian training schemes on 'Kerbcraft' (Department for Transport, 2011b).

A number of UK local authorities have introduced classroom oriented, paper-based activities into their training schemes, sometimes reducing the amount of on-street experience available to reduce costs or time. Paper based activities, such as word-searches and quizzes have been found to be less effective than practical training for improving on-street skills as they target knowledge acquisition only (Hammond et al., 2010, Fokides and Tsolakidis, 2008). Knowledge alone cannot be easily transferred from the classroom environment to the roadside. If classroom activities are to be introduced, there is a need to design them to target skill acquisition using more engaging and effective in-class activities. Virtual reality, interactive video and online multimedia used to replicate real roadside situations could all complement current delivery mechanisms, especially given that the target audience are already game literate by the time they reach primary school and gaming can be an effective learning medium when coupled to learning outcomes (Wong et al., 2007). These training aids would not be designed to replace any practical training, but to complement and reinforce the fundamental messages as part of a practical training scheme where classroom elements have been adopted.

This paper explores the potential for interactive hazard-identification video as an addition to the current range of classroom based activities available to road safety trainers in assisting the education of child pedestrians. We discuss the design and development of an interactive video designed to teach young children road crossing skills and through practical application in a school, find that it offers a usable and engaging addition to paper-based activities whilst improving certain crossing skills after a short amount of exposure. 


\subsection{Pedestrian Training in the United Kingdom}

A recent survey of local authorities in the United Kingdom indicated that $79 \%(n=43)$ who originally delivered Kerbcraft in schools had subsequently reduced the amount of practical training on offer (Hammond et al., 2013). Over 50\% had also introduced classroom-based activities despite research indicating that it is far less effective compared to practical training (Fokides and Tsolakidis, 2008) as paper based activities are often only designed to directly target knowledge. Many also indicated that financial pressures were the main threat to the training on offer with on-street activities being hardest hit in the drive to reduce costs. Under these circumstances, there is a need to ensure that where classroom-based activities are introduced, they increase the level of pedestrian skills at the roadside and not merely a child's knowledge. Interactive computer based activities may be a viable method for improving inclass training in order to realize this positive practical application on-street.

\subsection{The Scope for Interactive Video in Pedestrian Safety Education and Training}

Interactive video creates a multi-sensory learning environment (Zhang et al., 2006) and has been shown to increase an individual's ability to transfer information from the short to longterm memory (Cairncross and Mannion, 2007). Using auditory and visual cues, interactive video allows users to control elements of the video, increasing individual user engagement when compared to a non-interactive passive video. It may offer a cheap and yet effective alternative to virtual reality environments and can be generally defined as 'the use of computer systems to allow proactive and random access to video content based on queries or search targets' (Zhang et al., 2006). In this specific context, interactive video is defined as footage taken of actual activity which is subsequently hot-spotted using multimedia authoring software to allow players to engage in the scene at specific points via the computer mouse. A hot spot is a defined interactive area of a video which when clicked allows a specific action (in this case the generation of a pop-up window) to occur. Hot spots are not static and in fact move and change size as the video develops to ensure hazardous activity can be selected with a mouse. Areas of the video, (for example a specific hazard that moves between scenes) can be selected and used to trigger a follow-up response to the user to meet a learning outcome, in this case highlighting safe ways to reduce risk when a hazard is selected. Modern technologies allow interactive video to be used alongside other multimedia such as graphics, simulations and even other videos in order to attract a users' attention to a specific issue.

The use of interactive video for in-class road safety education was considered as early as the 1980s with systems reliant on dedicated interactive machines to read videos from discs (Chambers, 1997). Modern systems can run on a personal computer and recent studies have shown interactive video to be effective in improving roadside hazard awareness skills in kindergarten to third grade students (Glang et al., 2005). Alongside applications in road safety, Interactive Video also has successful applications in health and safety (Cherrett et al., 2009) and medical training (Dror et al., 2011b) demonstrating the potential to train users in 'hard' procedural skills (Cherrett et al., 2009), such as those required in road safety. Critically, interactive video has seldom been tested to determine its effectiveness in changing actual behaviour on-street and its impact on learning are largely unexplored (Zhang et al., 2006).

Because each video often contains footage of real, rather than simulated environments, the transfer of information to behaviour is aided by the fact that children will not have to 'translate' from a simulated to a real environment. A study of an animated road safety 
training tool by Foot et al. (2002) noted that some children found difficulty transferring from an animated to a real roadside environment, primarily due to their inability to visualise themselves in different settings.

The interactive videos developed by both Cherrett et al. (2009) and Dror et al. (2011a), were based on the same principal of asking players to identify hazardous behaviours by clicking directly on 'hot-spotted' elements as it played. Correct identification resulted in the video pausing and further interaction with the player taking place in the form of multiple choice questions and linked videos related to the particular hazard. In both demonstrations, the interactive video was split into several key sections where undesirable behaviours were shown and where hazards were correctly identified by the player, a hazard perception score would be shown. To complete the learning experience, the player was shown the footage again but from the point of view of the desirable 'best practice' behaviour.

This type of interactive video is therefore broadly based on Merrill's First Principles of Instruction (Merrill, 2002) which states that learning should: be problem centred, use relevant experience, include demonstration, allow the user to apply new skills and be integrated into a learners' everyday life. This type of interactive video is based on solving real world hazard identification problems, it focuses on a learner's basic understanding of the road environment and involves user-paced demonstrations which allow the user to practice and apply their hazard awareness and road safety skills in a safe but realistic environment.

\subsection{Methodology}

An interactive hazard perception video was developed for 6-7 year old children targeting the key skill of crossing safely between parked cars. The interactive video used footage from a carefully staged, undesirable on-street crossing behaviour and was based on a combination of the hazard perception and interactive video design principals demonstrated to be engaging and effective by Cherrett et al. (2009), Dror et al. (2011b) and Melson (2009). The video allowed users to interact and engage with footage designed to train children in a safer technique for crossing between parked cars from the safety of a classroom environment using a standard web browser.

Following the design and development of the interactive video, a usability study was carried out with 6-7 year old children $(n=15)$, to assess their level of engagement and enjoyment using a simple questionnaire and observations. The final video was then tested with groups of children $(n=43)$ from a different school in order to quantify its potential impact on their onstreet crossing skills using a before-and-after study with experimental (interactive video trained) and control groups (non-trained). Children were observed in a safe on-street environment, under full adult supervision, before and after using the interactive video in order to assess any change in behaviour as a result of learning from the resource.

\subsection{Interactive Video Development}

Filming the Video

The video storyline was based around two young children making an independent journey to a local amenity which involved crossing between parked cars where no safer crossing location was available.

Cherrett et al. (2009), Dror et al. (2011b) and Melson (2009) based their interactive videos around the premise of identifying and reacting to hazards. The video developed for this study 
followed a similar approach where a user is expected to identify and select hazards in order to interact and remain engaged. Two separate underlying videos were required: 1 ) the hazardidentification video, demonstrating a number of hazards and undesirable behaviour during the journey such as: running on the footway, bouncing a ball, failing to look in gateways and crossing between two parked cars without looking for on-coming vehicles or stopping at the footway edge. 2) A 'good practice' video outlining the safe use of footways and a desirable crossing procedure using UK government crossing guidelines.

\section{Making the Video Interactive}

The edited video clips were made interactive in the Flash authoring environment using custom scripts and native software features. The model video originally developed by Cherrett et al. (2009) was used as a template, following advice from road safety professionals, primary school teachers and psychologists, to ensure the user interface and functionality was suitable for young children. From this perspective, key features in the design included: i) an engaging colour scheme, ii) accompanying text with voice-over to aid children who have reading difficulties, iii) percentage scores with a star-rating system to ensure children with a range of numerical ability could understand the significance of their performance, iv) the introduction of a 'hints' system to aid hazard perception. The chronological elements of the new video were:

1) An introduction to the task.

2) A tutorial demonstrating how to interact with the video.

3) The interactive hazard perception video (Figure 3).

4) A safe practice section, breaking the safe procedure down into simple steps.

5) A reinforcement section, playing the entire safe crossing sequence.

The player watched the introduction and tutorial sections in full before progressing. The pace of the learning tool was controlled by the user who could move between the phases of the video by clicking on forward and backward arrows. In the hot-spotted hazard perception segment, the user could pause and rewind the video so that they could explore hazards in their own time. Visual hints were also provided to the player to help them identify hazards: 1) the mouse cursor would change from an arrow to a large hand, 2) an exclamation mark would appear next to the mouse cursor to draw the players' attention to the hazard (Figure 1). When a player clicked on a hazard, a pop-up box notified them that they had scored a point which was displayed on a scoreboard. The player simultaneously heard a loud braking sound-effect accompanied by on-screen text saying what the children should not have been doing. The player was then shown the corresponding video clip demonstrating the safe procedure. When the player had viewed the video once, they were given their intermediate score and if this was less than $100 \%$ were asked to play the video again to identify more hazards. On reaching the conclusion of the video for a second time, a final score was given before the player proceeded to the explanation and reinforcement segments.

\section{FIGURE 1}

In a similar vein to practical training, this educational resource is intended to be used at an age before independent pedestrian travel is recommended in order to reinforce safe behaviour before independent travel commences. Because of this, the children were also reminded, as part of the interactive video, that they should always have an adult or responsible person with them until they themselves are considered responsible enough for independent travel by their 
parents or legal guardians. This safety message, along with the fact that crossing between parked cars should only take place when there is not a safer alternative available, were also repeated verbally to participating children and reiterated to parents and legal guardians in writing.

\subsection{Identifying usability issues}

Questionaries' are a simple method for formally recording usability issues after playing the interactive video. The questionnaire methodology was based on the work of Sim et al. (2006) and Read and MacFarlane (2002) who highlighted the effectiveness of 'Smileyometers' in recording children’s opinions. Observation of issues was used alongside the questionnaire.

The questionnaire consisted of two phases, a single pre-play question to determine how 'good' the children anticipated the game would be and a set of post-play questions to determine how usable the children thought the game was, specifically how easy or hard they found it to click on dangerous activities portrayed in the video which is the primary hazard perception task the children undertake when playing the game.

Questions (Table 1) were written in simple English and approved by the school, to ensure the questions would be understood. Questions were executed on a one-to-one basis where each question was read out aloud and described to ensure that it was clear and to assist those with reading difficulties. All answers were given on a scale using a Smileyometer where a 'sad' face related to a negative opinion and a 'smiley' face related to a positive opinion depending on the question.

\section{TABLE 1}

The trial was conducted prior to the on-street skills assessment in a mixed-sex infants school (3-8 age range pupils) with over four times the national unauthorised level of absenteeism, approximately 50\% white-British and 50\% ethnic minority pupils (of whom over 1/3 speak English as an additional language), average free-school meals and average 'special needs'. The School received a 'Good' Ofsted rating. The participating children $(n=15)$ broadly reflected the characteristics of the school with one child being excluded from this analysis due to ambiguity on their answer sheet.

\subsection{On-Street Skills Assessment}

Two classes of 6-7 year old children, generally seen to be the target age group for pedestrian training, were selected by a local primary school to take part in an evaluation of the interactive video to assess its impact on roadside skills acquisition. One class was designated as the control group, and the other the experimental group, in a quasi-experimental study design.

Each group took part in a pre-training skills assessment where they were taken in groups of three to a quiet residential cul-de-sac, used primarily for parking. One child at a time was asked to lead an assessor (who feigned an inability to cross roads) across the road safely. This assessor was only present to stop the child should a potentially dangerous situation arise and was not tasked with leading or advising. During the crossing, the other assessor observed the child's behaviour and noted the presence or lack of key skills on a three point scale (good, satisfactory, poor) using an assessment record sheet: i) stopping at the kerb, ii) checking the 
parked cars are not about to move, iii) stopping at a safe location at the outside edge of the cars, iv) looking all around for traffic, v) crossing sensibly, vi) remaining aware while crossing. The remaining waiting children were positioned so their view of preceding children was obscured. This methodology is based on that developed by Whelen et al. (2008) to evaluate children's crossing proficiency as a result of taking part in Kerbcraft.

Following the pre-training skills assessment, the experimental group played the interactive hazard perception video to completion in class for approximately 20 to 30 minutes. The day following the interactive video training session, the experimental and control groups were reassessed in a post-training assessment at the same roadside location and using the same methodology. Immediately following this assessment, the children (in groups of three) were shown the correct crossing sequence, highlighting general mistakes made by the group and also told that they should always have an adult with them at the roadside until they are ready for independent school travel.

Pre and post-test assessment score records, of which a sample was cross-verified by the second assessor, were coded following the completion of the roadside study. Perfect behaviour was awarded two points, satisfactory behaviour was awarded one point and hazardous behaviour was awarded zero points.

In total, 43 children aged between six and seven years were involved in the study. In order to minimize school disruption, one class ( $\mathrm{N}=21,9$ females, 12 males) was randomly assigned the control condition and the other ( $\mathrm{N}=22,14$ females, 8 males) was assigned the experimental condition. Groups are matched for age and participant background.

\subsection{Results \& Discussion}

\section{Identifying usability issues}

The Smileyometer scores ranged from 1 to 5 with low scores indicating a negative/sad response and high scores indicating a positive/happy response (Table 2).

\section{TABLE 2}

In terms of how good the pupils found the activity, expectations were exceeded in four cases and met in 10 cases. One player stated that the video activity did not meet their expectations as they felt it was too hard. General ease of seeing and clicking on dangers ranged from 1 (too hard) to 5 (very easy) and this was reflected in the users' experience of how good they thought the game was. Mean scores of 3.7 and 3.2 indicated feedback was generally positive, while providing a level of challenge in order to engage users; a critical factor for successful learning. With the majority of users thinking that they did well at the activity there is an indication that the experience was positive. The results of the pilot suggested that for the majority of users, the interactive video did prove to be an engaging educational resource, but some experienced difficulty identifying and clicking on certain hazards. Future versions could include different activity levels based on increasing degree of difficulty.

Children were also asked to raise their hand with any technical and usability issues during the activity, which were then addressed immediately by the researcher. Technical issues were generally audio related and were addressed by increasing the volume using the system 
volume controls. Many of the children were not yet aware of how to do this and future interactive videos aimed at younger users should also implement on-screen volume controls within the game interface. Usability issues, which occurred rarely, related to either progressing through the video e.g. the player not clicking "next" to progress through scenarios, or issues clicking on hazards e.g. the player clicking on the screen when they saw a hazard, but not on the actual hazard itself.

\section{On-Street Skills Assessments}

The crossing proficiency of the majority of participants, in both experimental and control groups, improved to some extent between the pre and post-training assessments. This was unexpected as the largest improvements were expected to be observed in the experimental group. Unfortunately, during the experimental setup, the children had to be guided across two busy roads to reach the assessment site and this took place before the post-assessment in both the experimental and control group. While children were not being actively taught during these crossings, the procedures used to cross the road were explicitly safe and in essence replicated the training given in the interactive video.

One skill, which required children to check parked cars were not going to move before crossing, was not unintentionally demonstrated during these guided crossings as adults were able to carry out this skill subtly on the approach to the assessment site. Using a Wilcoxon signed ranks test, the experimental group demonstrated a statistically significant improvement after playing the interactive video $(\mathrm{Z}=-3.071, \mathrm{p}=<0.05)$, compared to the control group who did not significantly improve $(Z=-1.732, p=>0.05)$. Future studies could control for unintentional training by i) driving children from school to the test site, even over a very short distance or ii) setting up a mock street scene with parked cars within school grounds, or iii) selecting an assessment site that does not require road crossing in order to gain access. Further research is required to identify what specific parts of the video impacted on the children's cognition and what wider lessons can be learnt in terms of scene design and interaction methods.

Wider potential and implications for interactive video

Alongside road safety, interactive video has been used for training construction workers in 'hard' procedural skills to improve their awareness of health and safety (Cherrett et al., 2009). This paper develops those findings further to support the claim that interactive video does show potential for improving procedural behaviours and activities to better engage users in the material over a passive video that has no interactive elements. As well as being consistent with Merrill's First Principles, this type of interactive video is an example of technology enhanced learning as it uses Control (giving the user control of their learning), Challenge (providing a suitable level of difficulty) and Commitment (encouraging commitment to learning) (Dror, 2008, Dror et al., 2011b). Providing control to allow the learning to be self-paced is especially important to children as they may not be immediately familiar with the content or the multimedia system.

These principals encourage learners to be involved and motivated to participate and interact with their learning, drive engagement in the video and therefore increase the uptake of information when compared to passive versions. The nature of interactive video makes it especially suitable for exposing learners to other dynamic and changing situations aside from road safety, such as driving, flying, construction, military operations and medical procedures. In all these situations, the learners need to acquire information that they can use back in the 
'real world' environment and interactive videos can also help overcome language and cross cultural barriers as they rely on visual interactions making them useful in training people from various cultural and geographic backgrounds. Their adaptability also facilitates customisation, for example being able to update footage specific to local conditions and scenarios, and providing verbal information and on-screen prompts in multiple languages.

\section{Conclusions}

With the introduction of more paper based activities as part of practical child pedestrian training schemes it is pertinent to explore move effective in-class materials that are designed to improve skills and awareness rather than knowledge acquisition alone. This paper has shown that it is possible to develop an engaging, usable interactive video that, with further development, could be used as an additional training material, alongside practical training schemes such as Kerbcraft. Much like the paper-based materials currently used, interactive video is designed to be an addition to practical pedestrian training, which is still considered to be the most effective pedestrian skills development resource.

The results of this study suggest that interactive hazard-identification videos could positively impact on on-street behaviour but further research is required with more refined experimental procedures to fully appreciate the potential. One area that could be explored is the longerterm impact on behavioural change as a result of using interactive video using a study with before, after and delayed assessments. This would allow the behaviour retention time to be deduced and may indicate whether repeated exposure to interactive video may be useful in the longer-term in order for children to retain improved behaviour levels.

As with any behavioural change system, careful evaluation is required in order to ensure that that any future changes in pedestrian training activities are effective in targeting and improving desired on street behaviours and that no negative impact to current practical pedestrian training takes place.

\section{Acknowledgements}

The authors would like to thank the staff and students that took part in the study for their participation, help and support during the evaluation of the Interactive Video.

\section{REFERENCES}

Cairncross, S. \& Mannion, M. (2007). Interactive Multimedia and Learning: Realizing the benefits. Innovations in Education and Teaching International 38, 156-164.

Chambers, P. (1997). IV and SEN: Using interactive video with special educational needs pupils. British Journal of Educational Technology 28, 31-39.

Cherrett, T., Wills, G., Price, J., Maynard, S. \& Dror, I. (2009). Making Training More Cognitively Effective: Making Videos Interactive. British Journal of Educational Technology 40, 1124-1134. 
Department for Transport (2011a) Road Accident Data, 2010 [computer file]. Road Accident Statistics Branch. Colchester, Essex: UK Data Archive [distributor], December 2011. SN: 6926, http://dx.doi.org/UKDA-SN-6926-1.

Department for Transport (2011b) Strategic Framework for Road Safety. In Department for Transport (Ed. London, Department for Transport,.

Dror, I., Schmidt, P. \& O'connor, L. (2011a). A cognitive perspective on technology enhanced learning in medical training: great opportunities, pitfalls and challenges. Medical teacher 33, 291-296.

Dror, I., Schmidt, P. \& O’connor, L. (2011b). A cognitive perspective on technology enhanced learning in medical training: Great opportunities, pitfalls and challenges. Medical teacher 33, 291-296.

Dror, I. E. (2008). Technology enhanced learning : The good, the bad, and the ugly. Pragmatics and Cognition 2, 215-223.

Dumbaugh, E. \& Frank, L. (2007). Traffic Safety and Safe Routes to Schools: Synthesizing the Empirical Evidence. Transportation Research Record: Journal of the Transportation Research Board 2009, 89-97.

Fokides, E. \& Tsolakidis, C. (2008). Virtual Reality in Education: A Theoretical Approach for Road Safety Training to Students. European Journal of Open, Distance and E-Learning.

Foot, H., Tolmie, A., Thomson, J., Whelan, K., Sarvary, P. \& Morrison, S. (2002) Development and evaluation of computer based pedestrian training resource for children aged 5-11 years. London, Department for Transport.

Glang, A., Noell, J., Ary, D. \& Swartz, L. (2005). Using interactive multimedia to teach pedestrian safety: an exploratory study. Am J Health Behav 29, 435-442.

Hammond, J., Cherrett, T. \& Waterson, B. (2010) An evaluation of child pedestrian training in the UK: the scope for interactive technologies to aid teaching. 43rd Anual Meeting of the Universities' Transport Study Group (UTSG).

Hammond, J., Cherrett, T. \& Waterson, B. (2013). The Development of Child Pedestrian Training in the United Kingdom 2002-2011: A National Survey of Local Authorities. Journal of Transportation Safety \& Security, null-null.

Melson, K. (2009) 11.10.Interactive traffic training for children in Odense. CIVITAS Mobilis, European Union.

Merrill, M. D. (2002). First principles of instruction. Educational technology research and development 50, 43-59.

Pollack, K. M., Kercher, C., Frattaroli, S., Peek-Asa, C., Sleet, D. \& Rivara, F. P. (2012). Toward environments and policies that promote injury-free active living-it wouldn't hurt. Health \& Place 18, 106-114.

Read, J. \& MacFarlane, S. (2002). Endurability, Engagement and Expectations: Measuring Children's Fun. Interaction and Design.

Sim, G., MacFarlane, S. \& Read, J. (2006). All work and no play: Measuring fun, usability, and learning in software for children. Computers \& Education 46, 235-248.

Whelen, K., Towner, E., Errington, G. \& Powell, J. (2008) Road Safety Research Report No. 82. Evaluation of the National Child Pedestrian Training Pilot Projects. London, Department for Transport. 
Wong, W. L., Shen, C., Nocerna, L., Carriazo, E., Tang, F., Bugg, S., Narayanan, H., Wang, H. \& Ritterfeld, U. (2007) Serious Video Game Effectiveness. ACE '07. Hune 13-15, Salzburg, Austria.

Zhang, D., Zhou, L., Briggs, R. \& Nunamaker, J. (2006). Instructional video in e-learning: Assessing the impact of interactive video on learning effectiveness. Information and Management 43, 15-27. 


\section{FIGURES AND TABLES}

\section{FIGURE 1}

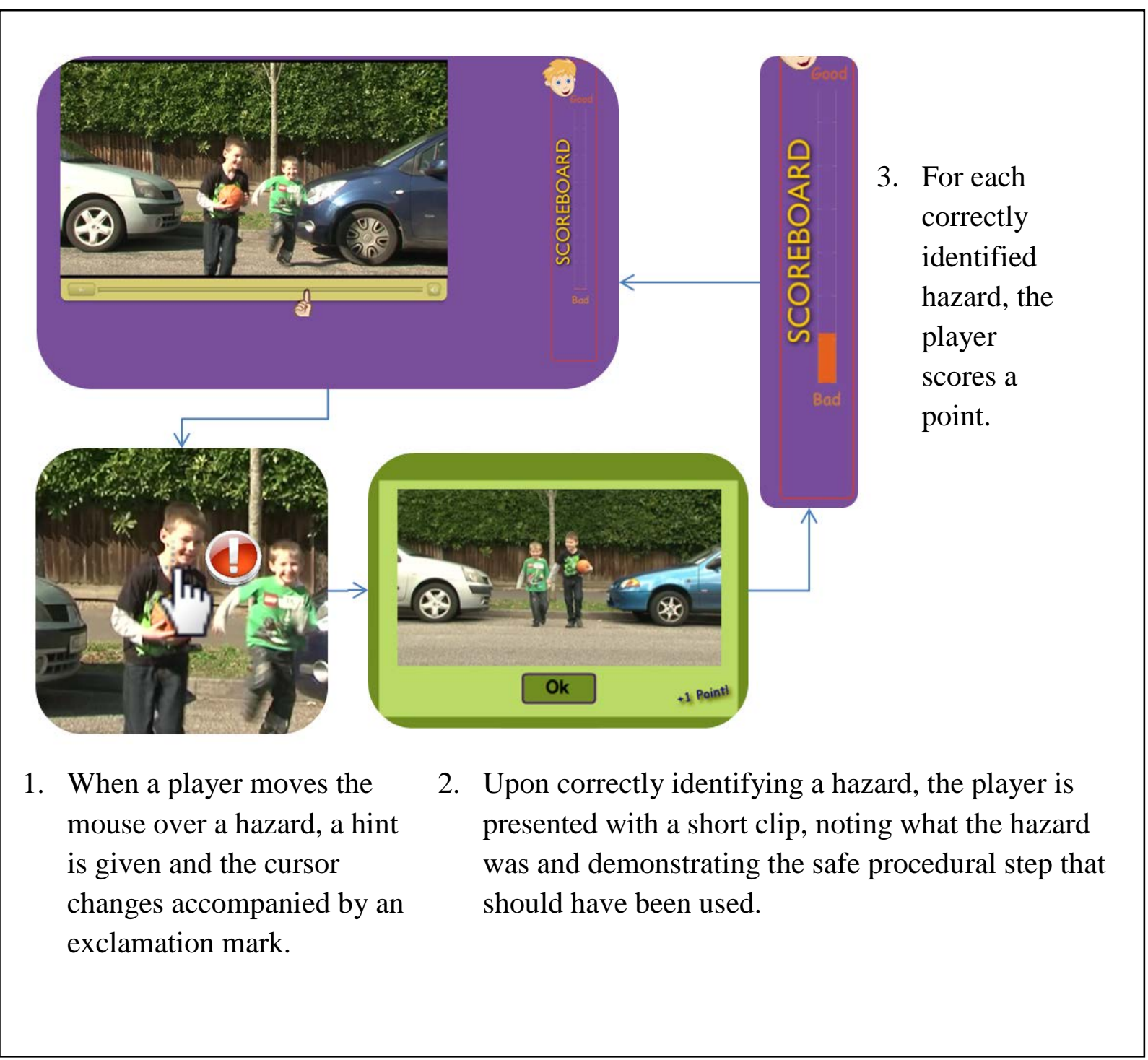

TABLE 1

Table 1: Usability Questions 


\begin{tabular}{|c|c|}
\hline Pre-play question & Description and rationale \\
\hline $\begin{array}{l}\text { How good do you think } \\
\text { this activity will be? }\end{array}$ & $\begin{array}{l}\text { Children were asked to say how good they thought the activity } \\
\text { would be before they started playing. This allows us to gauge the } \\
\text { extent to which the video subsequently met the users' } \\
\text { expectations. }\end{array}$ \\
\hline \multicolumn{2}{|l|}{ Post-play questions } \\
\hline $\begin{array}{l}\text { How good do you think } \\
\text { the activity was? }\end{array}$ & $\begin{array}{l}\text { Following gameplay, children were immediately asked how good } \\
\text { they actually found the video. Pre-play answers were hidden. }\end{array}$ \\
\hline $\begin{array}{l}\text { How easy was the } \\
\text { activity? }\end{array}$ & $\begin{array}{l}\text { Children were asked how easy they found the activity overall. } \\
\text { Clearly if the majority of children found the video too hard or } \\
\text { very easy to play then the difficulty level of the game would } \\
\text { require further assessment and refinement. }\end{array}$ \\
\hline $\begin{array}{l}\text { How easy was it to see } \\
\text { and click on the dangers? }\end{array}$ & $\begin{array}{l}\text { This question specifically asked children how easy they found it } \\
\text { to identify and select the hot-spotted hazards; the activity which } \\
\text { forms the basis of the hazard perception element of the game. } \\
\text { While challenge is a requirement to ensure children are engaged } \\
\text { with the material, it is clear that too much challenge would in } \\
\text { fact hinder the effectiveness of the game. }\end{array}$ \\
\hline $\begin{array}{l}\text { How well do you think } \\
\text { you did at the activity? }\end{array}$ & $\begin{array}{l}\text { This question aimed to gauge the child's perceived level of } \\
\text { success. }\end{array}$ \\
\hline
\end{tabular}

TABLE 2

Table 2: Identifying usability issues

\begin{tabular}{|l|c|}
\hline \multicolumn{1}{|c|}{ Question } & Mean Score \\
\hline $\begin{array}{l}\text { Before we start, how good do you think this } \\
\text { activity will be? }\end{array}$ & 4.3 \\
\hline How good do you think the activity was? & 4.5 \\
\hline How easy was the activity? & 3.7 \\
\hline $\begin{array}{l}\text { How easy was it to see and click on the } \\
\text { dangers? }\end{array}$ & 3.2 \\
\hline $\begin{array}{l}\text { How well do you think you did at the } \\
\text { activity? }\end{array}$ & 4.3 \\
\hline
\end{tabular}

